\title{
Therapeutic Advances in Urology: new crossroads in innovation, research, and clinical practice
}

Ther Adv Urol (2009) 1(1) 3-4 DOI: 10.1177/ 1756287209104682

(C) The Author(s), 2009. Reprints and permissions: http://www.sagepub.co.uk/ journalsPermissions.nav

Anthony Atala

This is the inaugural issue of the journal Therapeutic Advances in Urology. The mission of the journal is to publish original and review articles related to the latest therapeutic advances in urologic practice, research, and innovation. Trends in urologic practice vary widely and are constantly evolving. Our field has seen immense changes in just the past two decades. It is now hard to imagine stone management without lithotripsy as an option, or not using oral agents for prostatism or erectile dysfunction. These advances would often not have been possible where it not for the efforts invested in years of research and development. Surgical advances also usually evolve over time, but can often arise quickly, based on innovative concepts that are applied at a time of unexpected intra-operative findings.

As technological or surgical advances are being developed, new findings based on observation or evidence-based medicine may impact the use and application of these technologies. It would be fair to state that the only thing which remains constant in our field is change. Keeping up with these changes and having a clear understanding of the new trends in research and technology is essential for our practice. This journal will aim to provide a forum for the dissemination of this important information.

The journal will cover all areas of urology. A stellar international Editorial Board, composed of thought leaders in the field, has made a commitment to advance the mission of this journal. We are fortunate to have several of the Editorial Board members leading the specific urologic specialty areas of the journal as Associate Editors Peter Schlegel for the area of andrology, Jean de la Rosette for the area of endourology and minimally invasive surgery, Alan Wein for the area of incontinence and pelvic disorders, Alan Partin for the field of oncology, Goran Lackgren for the area of pediatric urology, and Francois Giuliano for the area of sexual dysfunction. We are indebted to the Editorial Board members for their efforts and commitment.

Publishing remains the single-most effective way of transferring important medical information. Sage Publications, the international publisher of this journal, has been in existence for almost half a century, and they are a world leader in their chosen professional markets, currently with over 500 journal titles. We are fortunate that Sage Publications, and the managing editor,
Correspondence to: Anthony Atala, MD Editor-in-Chief 5th Floor Watlington Hall, Medical Center Blvd.

Winston-Salem, North Carolina, United States, 27157, USA anthony.atalad sagepub.co.uk 
Matthew Thorne, have decided to diversify into the field of urology.

Visit SAGE journals online http://tau.sagepub.com

(SSAGEJOURNALS
We hope that you find this journal effective in bringing you timely information that will keep you abreast of the new developments in the field. Please do contact us with any suggestions that you may have as we launch this new exciting venture. On behalf of the Editorial Board and staff of the journal we thank you for your readership, and we are looking forward to serving your knowledge needs. 